\title{
The Impact of Adenotonsillectomy on Health- Related Quality of Life in Pediatric Patients
}

\author{
Shuaib Kayode Aremu ${ }^{1 *}$ and Omotosho Wasiu ${ }^{2}$ \\ ${ }^{1}$ Department of ENT, Federal Teaching Hospital, Ido-Ekiti / Afe Babalola University, Ado-Ekiti, Nigeria \\ ${ }^{2}$ Department of Surgery, Federal Medical Centre, Birnin Kebbi, Kebbi State, Nigeria
}

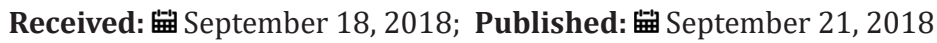

*Corresponding author: Shuaib Kayode Aremu, Department of ENT, Federal Teaching Hospital, Ido-Ekiti / Afe Babalola University, Ado-Ekiti, Nigeria

\begin{abstract}
Objective: To determine the impact of Adenotonsillectomy on Health-related quality of life (HRQoL) in children's before and after surgery.

Study Design: Prospective, Observational, before and after trial. 142 children who underwent Adenotonsillectomy were included in the study. Parents were made to fill pre and post-operative questionnaires which were customized from Tonsil and Adenoid health status instrument (TAHSI) and HR-QoL (Health-related quality of life) forms, one day prior to the surgery and 6 months after the surgery respectively, and the results were tabulated and analysed.
\end{abstract}

Setting: Tertiary paediatric otolaryngology practices.

Result: Out of the 142 children in the study 80 were male and 62 were female. Male to Female ratio being 1.3:1. Age group 1-4 years had highest number of patients while age group 9-12 had the least. Preoperatively the Mean score of domains for Sleep disturbances, Physical Symptoms, Emotional distress, Daytime functions, and Caregiver concern was 14.1, 15.83, 6.89, 7.54, and 13.78 respectively. After 6 months of the surgery, the score decreased to 4.65, 4.22, 4.32, 3.1 and 4.2 respectively. This shows a significant improvement in the symptom complex and the quality of the life.

Conclusion: Adenotonsillectomy leads to an improvement in the HRQoL in children as majority of parents were extremely satisfied with the surgical outcome. Almost all the parents reported decrease in Sleep disturbances, Physical Symptoms, Emotional distress, Daytime functions, and Caregiver concern.

Keywords: Adenotonsillectomy; Health-related quality of life; Obstructive Adenotonsillar Hyperplasia

\section{Introduction}

Globally, Adenotonsillectomy is arguably the most performed surgery by the paediatric otolaryngologist [1]. Its main indications are: obstructive sleep apnoea syndrome (OSAS), recurrent acute streptococcal pharyngotonsillitis, recurrent middle ear infections, hearing impairment, and, in selected cases, periodic fever with aphthous stomatitis, pharyngitis and adenopathy (PFAPA); all these conditions have significant repercussions on the quality of life (QoL) of patients and their families [2,3]. Generally, the greatest concern of any disease to physician, patients and caregivers refer to its physical consequences. However, the impact of a disease on the quality of life (QoL) of a patient, or his/her parent/guardian, should also be considered when choosing treatment approaches. The palatine tonsils, nasopharyngeal tonsils (adenoid), tubal and

lingual tonsils are the structures which form the Waldeyer's ring and are part of Mucosal Associated Lymphoid Tissue (MALT)/ Nasal Associated Lymphoid Tissue (NALT) system. This aggregation of lymphoid tissue is found at the entrance of the upper aero digestive tract. As such, the tonsils and adenoid are the body's first line of defence for protection of the lower airways and the gastrointestinal tract, as well as for development of antigenic memory by the host $[4,5]$. The principal disturbances of the tonsils and adenoid are infection and hyperplasia. Over years controversy exists as to the effect of removing tonsils and adenoid in children as they form an important part of the immune system implicating their removal only when the benefits of alleviating the preoperative morbidity outweigh the risks of surgery and the loss of the first line of defence 
of the aero digestive system [6]. But it is found that in long term, Adenotonsillectomy only removes the nidus for stimulated cellular and humoral immunity seen in tonsillitis, without any effect on the patient's normal immune function [7-9]. This study aims to determine the impact of Adenotonsillectomy on Health-related quality of life (HRQoL) in children's before and after surgery using questionnaires which were customized from Tonsil and Adenoid health status instrument (TAHSI) and HR-QoL (Health-related quality of life) forms. A detailed form of Health-related quality of Life questionnaire is attached in the Appendix (Table 1).

Table 1: TAHSI Components (Tonsil and Adenoid Health Status Instrument) and Scoring system.

\begin{tabular}{|c|c|}
\hline 6 Subscales & Scoring Pattern \\
\hline Infection & Not a problem \\
\hline Eating and swallowing & Not a problem \\
\hline Airway and breathing & very mild problem \\
\hline Health care utilization & moderate problem \\
\hline Cost of care & fairly bad problem \\
\hline Behavior & severe problem \\
\hline
\end{tabular}

\section{Materials and Methods}

This is a prospective, observational, before and after trial study.

\section{Inclusion Criteria}

A total of 142 children ( 80 boys and 62 girls, Male to female ratio was 1.3:1) between 1 - 12 years of age who underwent Adenotonsillectomy from May 2016 to July 2018 by the conventional dissection and snare method were included in the study (Table 2). Children who underwent isolated adenoidectomy, isolated tonsillectomy were also included in the study. Demographic data (age and sex) and tonsillar size were recorded for all patients, including those whose caregivers refused enrolment or dropped out of the study.

Table 2: Quality of life Parameters (Detail in Appendix).

\begin{tabular}{|c|c|}
\hline Problem List & Problem Scale \\
\hline Sleep disturbance & None \\
\hline Physical Symptoms & $\begin{array}{c}\text { Hardly any of the time, A little of } \\
\text { the time }\end{array}$ \\
\hline Emotional Distress & $\begin{array}{c}\text { Some of the time, A good bit of the } \\
\text { time }\end{array}$ \\
\hline Day time functions & Most of the time \\
\hline Caregiver Concerns & All the time \\
\hline
\end{tabular}

\section{Exclusion Criteria}

Children less than 1 year old or Children more than 12 years old; Children with nasal obstruction due to other causes like septal deviation, allergic rhinitis, nasal injury, and congenital nasal deformities and; Children of non-consenting parents or caregivers were excluded from the study. Among indications for Adenotonsillectomy were included Adenotonsillar hypertrophy with obstructive symptoms and recurrent Adenotonsillitis. The study protocol was approved by the ethical committee of our institution. Brodsky's assessment scale for tonsillar hyperplasia was used to grade the tonsil based on the following scale: 0 indicates that the tonsils do not impinge on the airway; $1+$ indicates less than $25 \%$ airway obstruction; $2+$ indicates $26 \%$ to $50 \%$ airway obstruction; $3+$ indicates $51 \%$ to $75 \%$ airway obstruction; and $4+$ indicates more than $75 \%$ airway obstruction [10]. The degree of obstruction of the nasopharyngeal airway was classified as showing either 'no obstruction' (grade I), or 'minimal' (grade II), or 'moderate' (grade III), or 'severe' (grade IV) obstruction [11]. Parents were made to fill pre and post-operative questionnaires which were customized (as some of the parameters were not feasible for our study) from Tonsil and Adenoid health status instrument (TAHSI) and HR-QoL (Health-related quality of life) forms, one day prior to the surgery and 6 months after the surgery respectively. The results were tabulated and analysed. Table 1 show the TAHSI scoring system and Table 2 shows 6 parameters which we included in our study for assessing Health-related quality of life (HRQoL) respectively.

\section{Statistical Analysis}

Table 3: Distribution of tonsils enlargement by Brodsky grade.

\begin{tabular}{|c|c|c|}
\hline Palatine Tonsil & Frequency & Percentage (\%) \\
\hline $0-25 \%(1+)$ & 19 & 13.3 \\
\hline $26-50 \%(2+)$ & 41 & 28.7 \\
\hline $51-75 \%(3+)$ & 63 & 44.3 \\
\hline$>75 \%(4+)$ & 19 & 13.7 \\
\hline Total & 142 & 100.0 \\
\hline
\end{tabular}

Data were collated and presented in descriptive format, tables, and graphs where appropriate. The data was entered in Microsoft Excel Workbook and was analysed in "SPSS 10 for Windows (Statistical Packages for Social Sciences 22.0 version)" software. Chi-square test was performed to compare the significant association between categorical variables and $p$ value $<0.05$ was taken as statistically significant. Out of the 142 children in the study 80 were male and 62 were female. Male to Female ratio being 1.3:1. Age group 1-4 years had highest number of patients while age group 9-12 had the least (Figure 1). Table 3 show the distribution of tonsils enlargement by Brodsky grade with Grade III and Grade IV tonsils seen in 44\% (63) and 13\% (19) of patients respectively out of 142 total patients. Adenoidal obstruction was seen in 91\% (129) of the children. Participants served as their own control as QoL changes were compared in individual participants before and after surgery. Before the surgery, mean score of the domain was very high for all domains and the survey. After surgery, however, the mean score was low for all domains and overall survey score. This indicated that there were large improvements in QoL from before surgery to six months after surgery respectively ( $p$ $=0.0001$ ) (Figure 2). Pre-operatively the Mean score of domains for Sleep disturbances, Physical Symptoms, Emotional distress, Daytime functions, and Caregiver concern was 14.1, 15.83, 6.89, 
7.54, and 13.78 respectively. After 6 months of the surgery, the score decreased to $4.65,4.22,4.32,3.1$ and 4.2 respectively. This shows a significant improvement in the symptom complex and the quality of the life $(\mathrm{p}=0.0001)$. Primary Haemorrhage (in theatre) was encountered in $7 \%$ of cases which was effectively controlled by electrocautery and nasal packing. Reactionary (within 24 hours of surgery) Haemorrhage was seen in 2 patient who was taken back to theatre and posterior nasal packing was done as it was secondary to adenoidectomy while fortunately no cases of secondary haemorrhage (after 48hours of surgery) were encountered. There were no cases requiring re-exploration / re-admission.

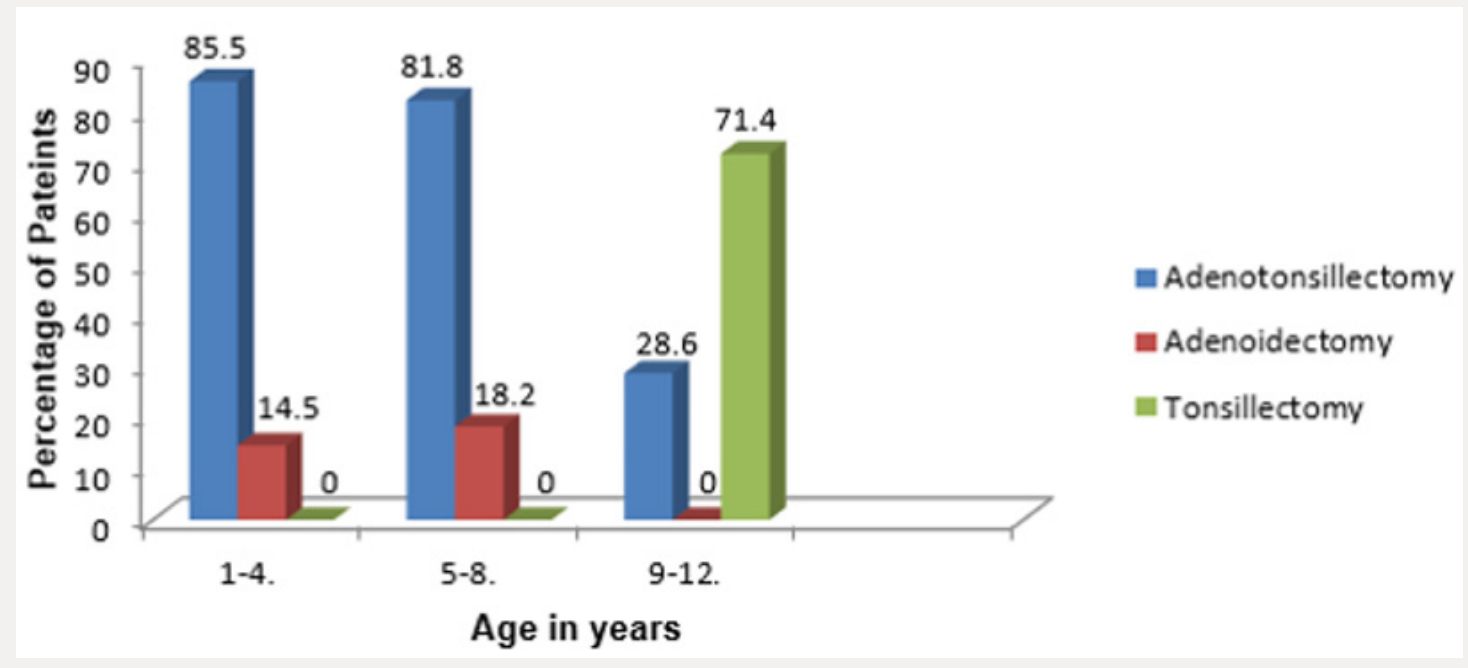

Figure 1: Distribution of type of surgery among age group.

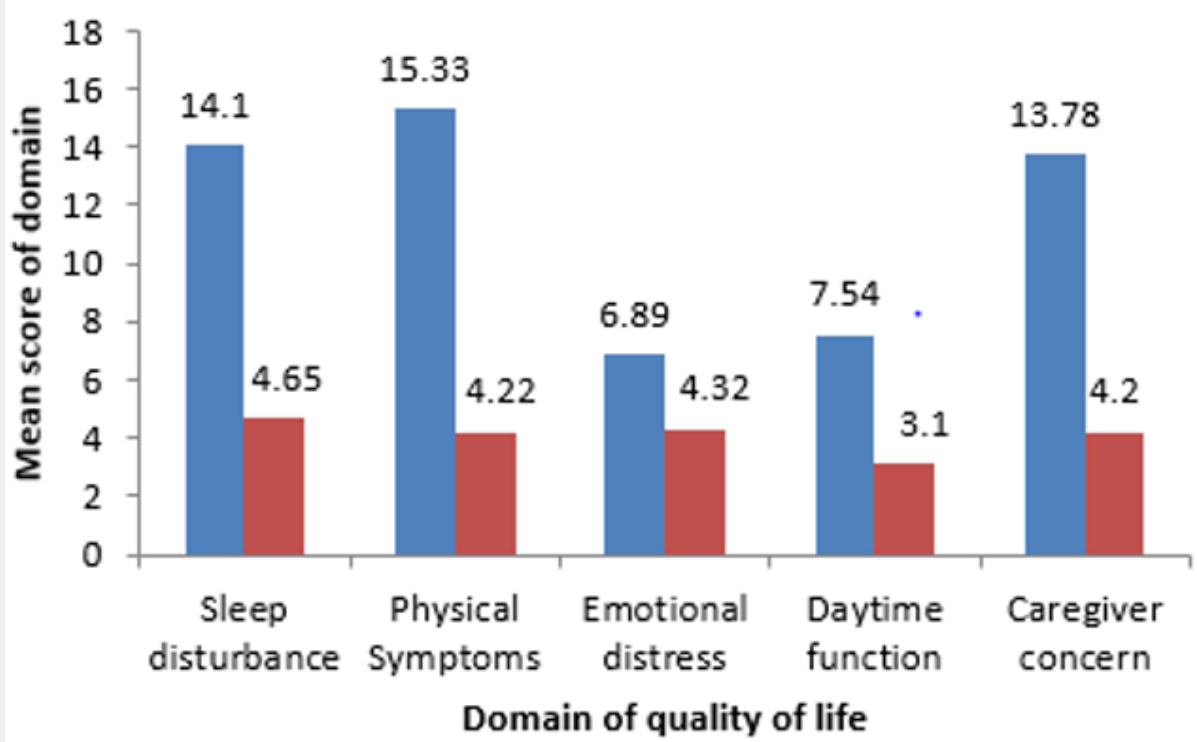

- Pre surgery

6 months post surgery

Figure 2: Comparison of mean score of domain quality of life, Pre and Post op.

\section{Discussion}

As decisions concerning resource allocation become increasingly stringent, it is important to understand the personal impact of diseases and their treatment beyond the standard medical morbidity or functional limitations so that this can be incorporated into the decision-making process. This has led to studies pertaining to outcome measures and effect of disease and management on HRQoL. Though Adenotonsillectomy is one of the most common surgeries performed in children [12] initially the medical line of management is started which includes analgesics for the initial 3 days followed by antibiotics like penicillin, Amoxiclav, Cephalosporins or Macrolides if symptoms persist. Surgical removal is done based on the AAP (American Academy of Paediatrics) guidelines for the indications of Adenotonsillectomy depicted in Table 4. Though various surgical tools are being used apart from the cold steel like laser, cryosurgery, harmonic scalpel, radiofrequency with collator being the latest and widely used tool, the surgical method remains the same. The post-operative morbidity and quality of life depends 
on multiple factors like indications of surgery, surgical technique, surgical complications and post-operative care with children generally facing lesser morbidity [13].

Table 4: AAP indications for Adenotonsillectomy.

\begin{tabular}{|c|c|}
\hline Tonsillectomy & Adenoidectomy \\
\hline \multicolumn{2}{|c|}{ Recurrent Throat Infection } \\
\hline Sore Throat & \\
\hline 7 in 1 year & \\
\hline 5 in each previous 2 years & Sleep disordered breathing \\
\hline 3 in each previous 3 years & Secretory otitis media \\
\hline $\begin{array}{c}\text { Associated with at least one of the } \\
\text { following }\end{array}$ & \\
\hline Temperature > 100.9 F (38.3 C) & \\
\hline $\begin{array}{c}\text { Cervical adenopathy } \\
\text { (tender/>2cms) }\end{array}$ & \\
\hline Tonsillar exudate & \\
\hline $\begin{array}{c}\text { Culture positive for group A beta } \\
\text { Hemolytic streptococcus }\end{array}$ & \\
\hline Sleep disordered breathing & \\
\hline
\end{tabular}

This study demonstrated that adenoidectomy \pm tonsillectomy was slightly more among males (56.3\%) than females (43.6\%) with a male to female ratio of $1.3: 1$. This was comparable with what that had been reported in similar studies [14-16]. However, another study demonstrated that both sexes are equally affected in the pubertal age group [17]. The mean age of children in this study was 3.9 years \pm 2.64 . This is smaller than what was reported by Ahmed et al, who reported age range of 0-18 years with a mean age of 5.44 years (+3.39 SD) and a median age of 5 years [18]. This finding could be because they included older children in their study. In an Open, randomised controlled trial where 300 children between 2-8 years of age with symptoms of adenotonsillar hypertrophy /infection were divided into two groups ,one with Adenotonsillectomy and the other with watchful waiting it was found that Adenotonsillectomy could be considered an indication for surgery for children with three to six episodes of throat infection in a year and not in children with mild symptoms of adenotonsillar hypertrophy or infection as the surgical benefit did not outweigh the effects of watchful waiting in mild cases [19].

In a hospital-based prospective study by Afolabi et al. [6] the most common indication for Adenotonsillectomy was obstructive symptoms and the reduction in pre-operative symptoms recorded were from $93.1 \%$ pre op to $10.3 \%$ post op for recurrent sore throat, from 100 to $13.8 \%$ for sleep disordered breathing and from $79.3 \%$ to $13.8 \%$ for eating \& swallowing disturbances which is similar to our results of reduction from Mean average score of 15.83 to 4.22 for physical symptom, from 14.1 to 4.65 for sleep disturbances and from 7.54 to 3.1 for Day time function disturbances. This study stressed the importance of parental satisfaction and that parents often expected improvement in quality of life of the child rather than just reduction in a symptom which formed the indication for the surgery. In a prospective study by Carneiro et al. [20] it was observed that parental satisfaction was significant for snoring, recurrent tonsillitis and use of antibiotics post Adenotonsillectomy like our study. However, rhinitis did not show significant improvement post operatively.

\section{Conclusion}

Adenotonsillectomy leads to an improvement in the HRQoL in children as majority of parents were extremely satisfied with the surgical outcome. Almost all the parents reported decrease in Sleep disturbances, Physical Symptoms, Emotional distress, Daytime functions, and Caregiver concern.

\section{References}

1. Derkey CS (1993) Paediatric otolaryngology procedures in United States: 1977-1987. Int J Paediatr Otorhinolaryngol 25(1-3): 1-12.

2. Darrow DH, Siemens C (2002) Indications for tonsillectomy and adenoidectomy. Laryngoscope 112(8 Pt 2 Suppl 100): 6-10.

3. Bellussi LM, Marchisio P, Materia E, Passàli FM (2011) Clinical guideline on adenotonsillectomy: the Italian experience. Adv Otorhinolaryngol 72 : 142-145.

4. Caulfield, Helen M (2008) Obstructive sleep apnoea in childhood. In: Scott-Brown's Otorhinolaryngology, Head and Neck Surgery, (1) (7th edn), Michael G, George GB, Martin JB (Eds.), Hodder Arnold, Great Britain, UK 85: 1102-1109.

5. Peyton S, Audie LW, Brian JW (2010) Pharyngitis and adenotonsillar disease. In: Cummings Otolaryngology, Head and Neck Surgery, ( $5^{\text {th }}$ edn), Paul WF, Bruce HH, Valerie JL (Eds.). Mosby Elsevier, Philadelphia, USA pp. 195-197.

6. Afolabi OA, Alabi BS, Ologe FE, Dunmade AD, Segun Busari S (2009) Parental satisfaction with post-adenotonsillectomy in the developing world. Int J Pediatr Otorhinolaryngol 73(11): 1516-1519.

7. Kaygusuz I, Gödekmerdan A, Karlidag T, Keles E, Yalcin S, et al. (2003) Early stage impacts of tonsillectomy on immune functions of children. Int J Pediatr Otorhinolaryngol 67(12): 1311-1315.

8. Zielnik Jurkiewicz B, Jurkiewicz D (2002) Implication Of Immunological Abnormalities After Adenotonsillotomy. Int J Pediatr Otorhinolaryngol 64(2): 127-132.

9. Kaygusuz I, Alpay HC, Gödekmerdan A, Karlidag T, Keles E, et al. (2009) Evaluation of long-term impacts of tonsillectomy on immune functions of children: A follow-up study. Int J Pediatr Otorhinolaryngol 73(3): 445449.

10. Brodsky L, Moore L, Stanievich JF (1987) A comparison of tonsillar size and oropharyngeal dimensions in children with obstructive adenotonsillar hypertrophy. Int J Pediatr Otorhinolaryngol 13(2): 149157.

11. Orji FT, Okolugbo NE, Ezeanolue BC (2010) The role of adenoidal obstruction in the pathogenesis of otitis media with effusion in Nigerian children. Niger J Med 19(1): 62-68.

12. Rosenfeld R, Bhaya M, Bower C, Brookhouser PE, Chan KH et al. (2000) Impact of tympanostomy tubes on child quality of life. Arch Otolaryngol Head Neck Surg 126(6): 585-592.

13. Piltcher OB, Scarton FB (2005) Antibiotic use in tonsillectomies: therapeutic or prophylactic?. Required or excessive? Rev Bras Otorrinolaringol 71(5): 686-690.

14. De Serres LM, Derkay C, Sie K (2002) Impact of adenotonsillectomy on quality of life on children with obstructive sleep disorders. Arch Otolaryngol Head Neck Surg 128(5): 489-496.

15. Mitchell R, Kelly J (2005) Quality of Life after Adenotonsillectomy for SDB in Children. Otolaryngol Head Neck Surg 133(4): 569-572. 
16. Mitchell R, Kelly J, Call E (2004) Quality of life after adenotonsillectomy for obstructive sleep apnoea in children. Arch Otolaryngol Head Neck Surg 130(2): 190-194.

17. Lim J, Mckean MC (2011) Adenotonsillectomy for obstructive sleep apnoea in children. Cochrane database of systemic reviews 2:1-17.

18. Ahmed AO, Aliyu I, Kolo ES (2014) Indications for tonsillectomy and adenoidectomy: Our experience. Niger J Clin Pract 17(1): 90-94.
19. Staaij BK, Akker EH, Rovers MM, Hordijk GJ (2004 ) Effectiveness of adenotonsillectomy in children with mild symptoms of throat infections or adenotonsillar hypertrophy: open, randomised controlled trial. BM] 329: 651 .

20. Carneiro LEP, Neto GCR, Camera MG (2009) Adenotonsillectomy Effect on the Life Quality of Children with Adenotonsillar Hyperplasia. Int. Arch.Otorhinolaryngol 13(3): 270-276.
This work is licensed under Creative Commons Attribution 4.0 License

To Submit Your Article Click Here:

Submit Article

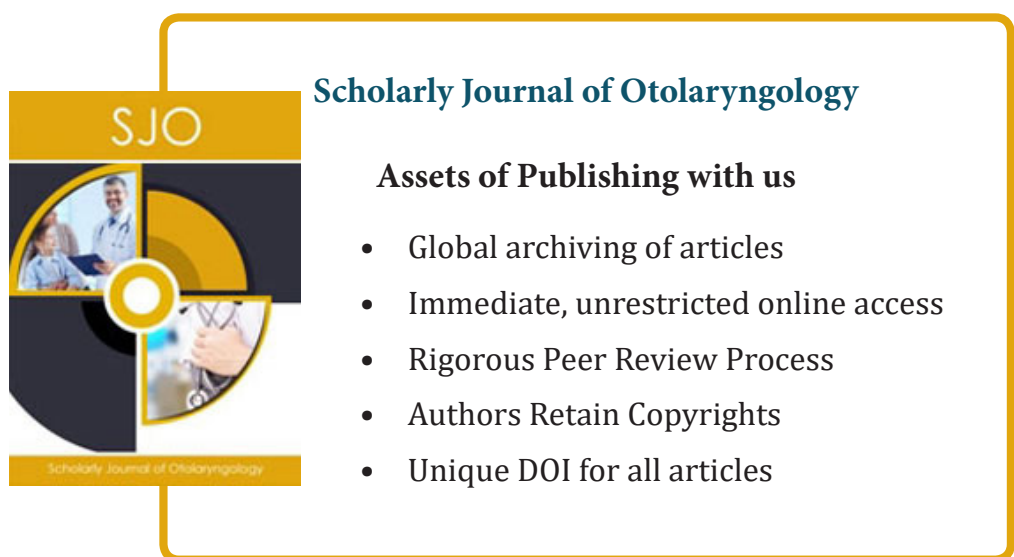

